\title{
Impact of demographic, environmental, socioeconomic, and government intervention on the spreading of COVID-19
}

\author{
Fazla Rabbi Mashrur ${ }^{\mathrm{a}, *}$, Amit Dutta Roy ${ }^{\mathrm{a}}$, Anisha Parsub Chhoan ${ }^{\mathrm{a}}$, Sumit Sarker ${ }^{\mathrm{a}}$, \\ Anamika Saha ${ }^{\text {d, S.M. Naimul Hasan }}{ }^{\text {d,e }}$, Shumit Saha ${ }^{\text {b,c }}$ \\ ${ }^{a}$ Department of Biomedical Engineering, Khulna University of Engineering \& Technology, Bangladesh \\ ${ }^{\mathrm{b}}$ Institute of Biomedical Engineering, University of Toronto, Canada \\ ${ }^{\mathrm{c}}$ eHealth Innovation, University Health Network, Canada \\ ${ }^{\mathrm{d}}$ University Health Network, Canada \\ ${ }^{\mathrm{e}}$ Department of Medical Biophysics, University of Toronto, Canada
}

\section{A R T I C L E I N F O}

\section{Keywords:}

COVID-19

Severe acute respiratory syndrome coronavirus 2

Demographic

Environmental

Government intervention

\begin{abstract}
A B S T R A C T
Background: The coronavirus disease 2019 (COVID-19) pandemic is a worldwide epidemiological emergency, and the risk factors for the multiple waves with new COVID-19 strains are concerning. This study aims to identify the most significant risk factors for spreading COVID-19 to help policymakers take early measures for the next waves.

Methods: We conducted the study on randomly selected 29 countries where the pandemic had a downward trend in the daily active cases curve as of June 10, 2020. We investigated the association with the standardized spreading index and demographical, environmental, socioeconomic, and government intervention. To standardize the spreading index, we accounted for the number of tests and the timeline bias. Furthermore, we performed multiple linear regression to identify the relative importance of the variables.

Results: In the correlation analysis, air pollution, $\mathrm{PM}_{2.5}(\mathrm{r}=0.37, p=0.0466)$, number of days to impose lockdown from first case $(\mathrm{r}=0.38, p=0.0424)$ and total confirmed cases on the first lockdown $(\mathrm{r}=0.61, p=$ $0.0004)$ were associated with outcome measures. In the adjusted model, air pollution $\left(\beta_{1}=4.5, p=0.0127,|\mathrm{t}|=\right.$ 3.1) and overweight prevalence $\left(\beta_{1}=4.7, p=0.0187,|\mathrm{t}|=2.9\right)$ were the most significant exposure variable for spreading of COVID-19.

Conclusion: Our findings showed that countries with larger $\mathrm{PM}_{2.5}$ values and comparatively more overweight populations are at higher risk of spreading COVID-19. Proper preventive measures may reduce the spreading.
\end{abstract}

\section{Introduction}

Coronavirus Disease-2019 (COVID-19) is a global pandemic affecting all the six inhabitant continents worldwide, infecting nearly 133,853,626 individuals of all ages as of 8 th April 2, $021 .{ }^{1}$ An explanatory statement of the Imperial College advised that the infection may cover more than $90.0 \%$ of the world's people, killing 40.6 million people if no reduction actions are taken to combat the virus. ${ }^{2}$ Therefore, the knowledge of important risk factors can help the policymakers to take early measures to reduce the infection rate.

Static risk factors like demographical, environmental, socioeconomic conditions are not equally important while it comes to spreading the COVID-19. ${ }^{3,4}$ Earlier Chinese, Italian, and Spanish studies identified risk factors of COVID-19 diagnosed individuals, like hypertension, diabetes, cardiovascular disease, older age, and male sex, ignoring the demographical or socioeconomic factors. ${ }^{5,6}$ Later, studies performed on a broader population for a specific area aimed to find clinical and demographical risk factors for testing positive for COVID-19. ${ }^{3,4}$ Moreover, studies also found that imposed lockdown and restricting public gatherings significantly reduced the transmission of COVID-19. ${ }^{7,8}$ Additionally, environmental risk factors were also studied where air pollution was associated with the spreading of COVID-19, while temperature and humidity had an inconsistent relationship with the transmission of COVID-19. 8,9

However, to the best of the authors' knowledge, no study considers demographic, environmental, socioeconomic, and government

\footnotetext{
* Corresponding author. Khulna University of Engineering \& Technology, Khulna, 9203, Bangladesh.

E-mail addresses: rabbi.mashrur@gmail.com (F.R. Mashrur), shumit.saha@mail.utoronto.ca (S. Saha).
} 
intervention together to give supportive information about the risk factors of COVID-19. Moreover, one important shortcoming of most of the aforementioned studies was they used the confirmed cases of COVID19 and did not account for the number of testing. ${ }^{3,4}$ Furthermore, modeling studies should consider this time difference to get an unbiased estimate of the spread of COVID-19.

To address these gaps, in this study, we aimed to investigate the impact of the most significant risk factors of demographic, environmental, socioeconomic, and government intervention on spreading of COVID-19, accounting for the factors of the number of testing and timeline of spreading the disease.

\section{Methodology}

We conducted a cross-sectional study based on data collected from publicly available online sources. For this purpose, we did not require any research ethics approval.

We randomly selected 29 countries around the world where the COVID-19 pandemic maintained a downward trend in the active cases as of June 10, 2020, obtained from real-time statistics website "Worldometer". ${ }^{1}$ We excluded the countries that used pooling testing methods and countries that have an upward trend in the active cases as of June $10,2020$.

\subsection{Outcome measure: standardized spreading index}

The total confirmed cases (TC) were dependent on the total number of tests (TT) conducted by a country. We divided the TC with TT to quantify the true nature of spreading, standardized spreading index $\left(T_{s}\right)$ using equation (1). To select a standardized timeline for each country, we used the well-known bell-shaped active cases curve. ${ }^{1}$ We estimated a peak point on the curve for every country, selecting it as the adjudged peak. Then, we chose another point at $7( \pm 2)$ days interval from that adjudged peak (Fig. 1). In this specific point (green point in Fig. 1), we collected the value of $T C$ and $T T$ to calculate $T_{s}(\%)$. We collected $T C$ and TT values from openly available COVID-19 database of "Our World in Data". ${ }^{1}$

Standardized spreading index, $T_{s}=\frac{T C}{T T} \times 100$

\subsection{Exposure variables}

We collected exposure variables related to demographical, environmental, socioeconomic, and government intervention. All the data were obtained from several web-based databases and sites.

\subsubsection{Demographical variables}

We used the total population (number-of-people), population density, number of days from global 1st case to adjudged peak (number-ofdays), number of days from global 1st case to country's 1st case (number-of-days), urban population, smoking prevalence, alcohol consumption, and overweight prevalence as the exposures for the demographic variable. The urban population (\%) and the population density $\left(\mathrm{p} / \mathrm{km}^{2}\right)$ were collected from "Worldometer". ${ }^{1}$ The number of days from global 1 st case to adjudged peak and the number of days from global 1st case to country's 1st case were collected from local news portals and press releases considering 31st December as global 1st case. We collected the smoking prevalence (\%) for any tobacco, alcohol consumption (per capita) for people aged 15 years or more and overweight prevalence (BMI $>25, \%$ ) for adults more than 18 years old from Global Health Observatory data repository of the World Health Organization. ${ }^{10}$

\subsubsection{Environmental variables}

For the environmental variables, we used temperature, relative humidity, and air pollution index. We collected both the average temperature $\left({ }^{0} \mathrm{C}\right)$ and the average relative humidity from "timeanddate.com". ${ }^{11}$ They were calculated as an average from the date of the first global COVID-19 reported case till April 2020. Furthermore, we used the exposure to atmospheric particulate matter less than $2.5 \mu \mathrm{m}\left(\mathrm{PM}_{2.5}\right)$ in $\mu \mathrm{g} / \mathrm{m}^{3}$ unit for calculating the air pollution profile. The air pollution profile was collected from "IQAir.com". ${ }^{12}$

\subsubsection{Socioeconomic variables}

In the socioeconomic variables, we used per capita income, literacy rate, and healthcare expenditures. We collected the literacy rate (\%), the income (per capita, USD), and the healthcare expenditures (per capita, USD) from open database of the World Bank. ${ }^{13}$

\subsubsection{Government intervention}

For government intervention, we collected data on the imposed lockdown (number of days to impose lockdown from the first case \& total confirmed cases on the first lockdown), the stringency of the government response (GRSI 1000 cases to 2 weeks and GRSI 1st case to 2 months) and contact tracing (CT 1st case to 2 weeks).

The number of days to impose lockdown (number-of-days) from the first case and the total confirmed cases (number-of-cases) on the first

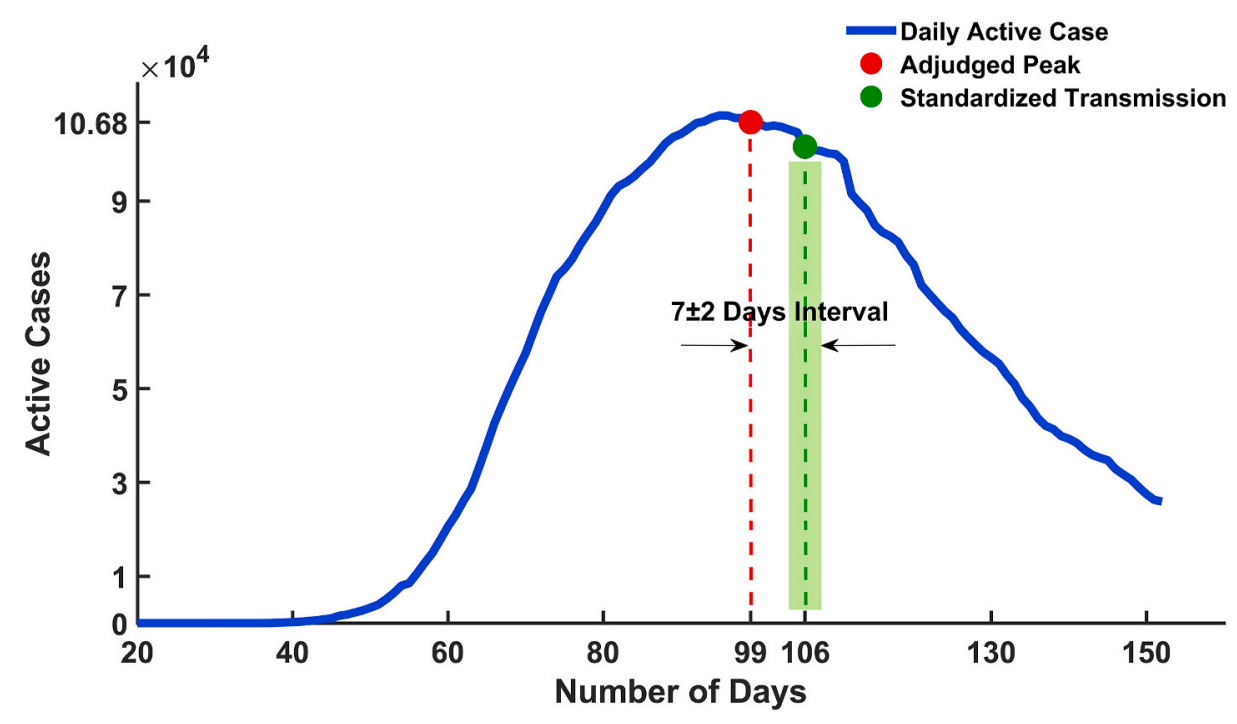

Fig. 1. Illustration of standardized spreading index. 
Table 1

Characteristics of analyzed countries $(n=29)$.

\begin{tabular}{|c|c|c|c|}
\hline Variables & & Median & IQR \\
\hline Outcome Measure & $\mathrm{T}_{\mathrm{s}},(\%)$ & 8.1 & $3.4-12$ \\
\hline \multirow{8}{*}{ Demographical } & Total population, number of people & 10582312 & $4723039-48457528$ \\
\hline & Population density, $\mathrm{p} / \mathrm{km}^{2}$ & 99 & $27-209$ \\
\hline & Number of days from global 1st case to adjudged peak, number of days & 125 & $108-139$ \\
\hline & Number of days from global 1st case to country's 1st case, number of days & 58 & $27-63$ \\
\hline & Urban population, $\%$ & 80 & $69-86$ \\
\hline & Smoking prevalence, $\%$ & 21 & $16-27$ \\
\hline & Alcohol consumption, per capita & 9.3 & $4.8-12$ \\
\hline & Overweight prevalence, $\%$ & 59 & $56-63$ \\
\hline \multirow[t]{3}{*}{ Environmental } & Temperature, ${ }^{\circ} \mathrm{C}$ & 7.9 & $5.4-16$ \\
\hline & Relative humidity, \% & 69 & $63-77$ \\
\hline & Air pollution $\left(\mathrm{PM}_{2.5}\right), \mu \mathrm{g} / \mathrm{m}^{3}$ & 14 & $9.6-22$ \\
\hline \multirow[t]{3}{*}{ Socioeconomic } & Per capita income, USD & 31754 & $17287-59362$ \\
\hline & Literacy rate, $\%$ & 99 & $98-100$ \\
\hline & Healthcare spending, USD & 2283 & $502-5005$ \\
\hline \multirow[t]{5}{*}{ Government. Intervention } & Number of days to impose lockdown from first case, Number of days & 23 & $15-45$ \\
\hline & Total number of cases on first lockdown, number of cases & 602 & $188-2248$ \\
\hline & GRSI 1 st case to 2 weeks & 17 & $12-25$ \\
\hline & GRSI 1000 case to 2 weeks & 77 & $63-88$ \\
\hline & CT 1 st case to 2 weeks & 1.0 & $0.47-2.0$ \\
\hline
\end{tabular}

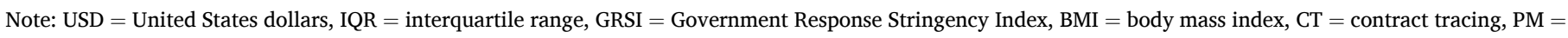
fine particulate matter.

lockdown were obtained from local news portals, press releases, and briefings. We considered the first restrictions imposed in the movement of the general mass for public health safety in an area of a country or the entire country as the start of the lockdown for a country. In this regard, Wikipedia ${ }^{14}$ assisted in validating our references further. We obtained the data of stringency of the government response from Oxford COVID-19 Government Response Tracker, Blavatnik School of Government. ${ }^{15}$ The government response stringency index (GRSI) was used to measure the strictness of the government and was calculated from publicly available information on 17 indicators of government responses. To calculate GRSI 1st case to 2 weeks and GRSI 1000 cases to 2 weeks, we used the average GSRI values of two weeks following the first confirmed case and the 1000 confirmed cases, respectively. Besides, we collected the contact tracing data from the database of "Our World in Data". ${ }^{16}$ We calculated the average value following two weeks from the first confirmed case for the contact tracing (CT 1st case to 2 weeks).

\subsection{Statistical analysis}

We used descriptive statistics to report the interquartile range and the median (Table 1). We performed Pearson or Spearman correlation analysis between the exposure variables and outcome measure $T_{s}(\%)$. To assess the normality of the data, we used the Shapiro-Wilk test.

Furthermore, we performed multiple linear regression (MLR) analysis to measure the relative importance of the exposure variables. By calculating the variance inflationary factor of each variance, we investigated the collinearity of all exposure variables that were considered within acceptable limits, with a maximum value below 4.0. Firstly, we developed the unadjusted MLR model for all variables except the confounding variables. Then, we adjusted for the possible confounding variables. We reported the standardized slope $\left(\beta_{1}, 95 \% \mathrm{CI}\right),|\mathrm{t}|$ value, $\mathrm{p}$ value, and $\mathrm{R}^{2}$ to evaluate the regressions in both unadjusted and adjusted models. Statistical analyses were performed by $\mathrm{R}$ (version 4.0.0), and two-tailed $\mathrm{p}<0.05$ was considered as significant.

\section{Result}

We selected 29 countries, of which 16 were from Europe, 8 from Asia, 2 from Australia, 1 from Africa, 1 from South America, and 1 from North America for the analyses. Table 1 shows the median and IQR of our outcome measures and exposure variables.

Table 2 shows the correlation analyses between the exposure variables and $T_{s}$. The results showed significant associations between government intervention and $T_{s}$. The number of days to impose lockdown from first case $(r=0.38, p=0.0424$, Fig. 2-b) and the total confirmed cases on the first lockdown $(\mathrm{r}=0.61, p=0.0004)$ had significant positive correlations. Only the air pollution, $\mathrm{PM}_{2.5}(\mathrm{r}=0.37, p$ $=0.0466$, Fig. 2-a) was significant amongst environmental related variables. No demographical and socio-economic variables were significantly correlated with $T_{s}$. However, overweight prevalence had a borderline significance with $T_{s}(\mathrm{r}=0.35, p=0.0601)$.

Table 3 demonstrates the results of the MLR analysis to estimate the relative importance among the risk factors for measuring $T_{s}$. In the unadjusted model, overweight prevalence $\left(\beta_{1}=3.5, p=0.0257,|\mathrm{t}|=2.5\right.$ ) was significant among the demographical variables. The air pollution,

Table 2

Correlation analysis of standardized spreading index and risk factors for the spreading of COVID-19.

\begin{tabular}{|c|c|c|c|}
\hline Variables & & $\mathrm{r}$ & $\mathrm{p}$ \\
\hline \multirow[t]{8}{*}{ Demographical } & Total population, number of people & 0.28 & 0.1423 \\
\hline & Population density, $\mathrm{p} / \mathrm{km}^{2}$ & 0.13 & 0.4882 \\
\hline & $\begin{array}{l}\text { Number of days from global 1st } \\
\text { case to adjudged peak, number of } \\
\text { days }\end{array}$ & 0.11 & 0.5564 \\
\hline & $\begin{array}{l}\text { Number of days from global 1st } \\
\text { case to country's 1st case, number } \\
\text { of days }\end{array}$ & 0.05 & 0.7905 \\
\hline & Urban population, $\%$ & 0.13 & 0.5111 \\
\hline & Smoking prevalence, $\%$ & -0.097 & 0.6183 \\
\hline & Alcohol consumption, per capita & -0.27 & 0.1539 \\
\hline & Overweight prevalence, $\%$ & 0.35 & 0.0601 \\
\hline \multirow[t]{3}{*}{ Environmental } & Temperature, ${ }^{\circ} \mathrm{C}$ & 0.3 & 0.1126 \\
\hline & Relative humidity, \% & -0.22 & 0.2515 \\
\hline & Air pollution $\left(\mathrm{PM}_{2.5}\right), \mu \mathrm{g} / \mathrm{m}^{3}$ & 0.37 & 0.0466 \\
\hline \multirow[t]{3}{*}{ Socioeconomic } & Per capita income, USD & 0.032 & 0.8690 \\
\hline & Literacy rate, $\%$ & -0.19 & 0.3300 \\
\hline & Healthcare spending, USD & -0.2 & 0.3081 \\
\hline \multirow[t]{5}{*}{$\begin{array}{l}\text { Government } \\
\text { Intervention }\end{array}$} & $\begin{array}{l}\text { Number of days to impose } \\
\text { lockdown from first case, number } \\
\text { of days }\end{array}$ & 0.38 & 0.0424 \\
\hline & $\begin{array}{l}\text { Total number of cases on first } \\
\text { lockdown }\end{array}$ & 0.61 & 0.0004 \\
\hline & GRSI 1st case to 2 weeks & 0.04 & 0.8322 \\
\hline & GRSI 1000 case to 2 weeks & -0.14 & 0.4535 \\
\hline & CT 1 st case to 2 weeks & -0.16 & 0.4066 \\
\hline
\end{tabular}

Note: significant associations $(\mathrm{p}<0.05)$ are shown in bold. 


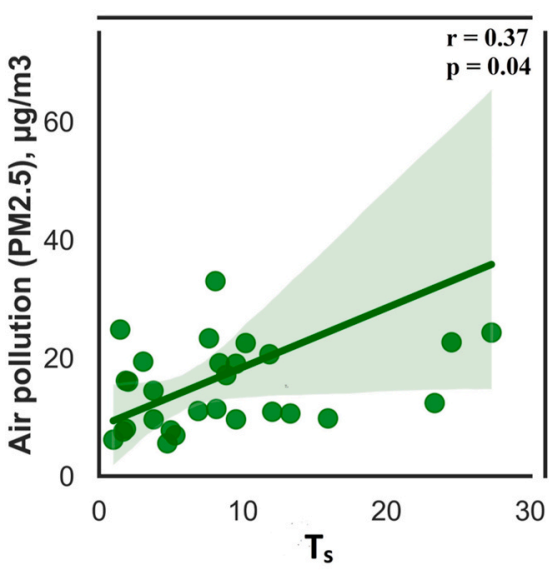

(a)

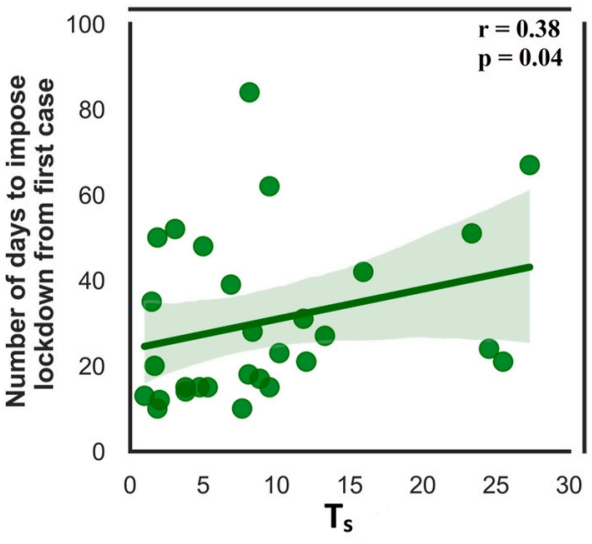

(b)

Fig. 2. Correlation plot between standardized spreading index $\left(T_{s}\right)$ and significant exposure variables (a) number of days to impose lockdown from first case (b) air pollution $\left(\mathrm{PM}_{2.5}\right), \mu \mathrm{g} / \mathrm{m} .^{3}$.

Table 3

Unadjusted multiple regression analysis of standardized spreading index and risk factors for the spreading of COVID-19.

\begin{tabular}{|c|c|c|c|c|}
\hline \multirow[t]{2}{*}{ Variables } & & \multicolumn{3}{|l|}{ Unadjusted Model } \\
\hline & & $\boldsymbol{\beta}_{1}(95 \% \mathrm{CI})$ & $p$ & $|t|$ \\
\hline \multirow[t]{4}{*}{ Demographical } & Urban population, $\%$ & $-1.4(-4.9$ to 2.1$)$ & 0.3973 & 0.88 \\
\hline & Smoking prevalence, $\%$ & $3.1(-0.81$ to 7.0$)$ & 0.1106 & 1.7 \\
\hline & Alcohol consumption, per capita (USD) & $-0.78(-4.6$ to 3.0$)$ & 0.6636 & 0.45 \\
\hline & Overweight prevalence, $\%$ & $3.5(0.50$ to 6.5$)$ & 0.0257 & 2.5 \\
\hline \multirow[t]{3}{*}{ Environmental } & Temperature, ${ }^{\circ} \mathrm{C}$ & $0.41(-2.8$ to 3.6$)$ & 0.7826 & 0.28 \\
\hline & Relative humidity, $\%$ & $0.56(-2.2$ to 3.3$)$ & 0.6654 & 0.44 \\
\hline & Air pollution $\left(\mathrm{PM}_{2.5}\right), \mu \mathrm{g} / \mathrm{m} 3$ & $4.2(1.4$ to 6.9$)$ & 0.0066 & 3.2 \\
\hline \multirow[t]{3}{*}{ Socioeconomic } & Per capita income, USD & $3.6(0.067$ to 7.1$)$ & 0.0464 & 2.2 \\
\hline & Literacy rate, $\%$ & $3.3(0.20$ to 6.4$)$ & 0.0386 & 2.3 \\
\hline & Healthcare spending, USD & $0.76(-1.9$ to 3.4$)$ & 0.5491 & 0.62 \\
\hline \multirow[t]{6}{*}{ Government Intervention } & Number of days to impose lockdown from first case, number of days & $5.5(1.0$ to 10$)$ & 0.0201 & 2.6 \\
\hline & Total number of cases on first lockdown, number of cases & $0.43(-3.0$ to 3.9$)$ & 0.7943 & 0.27 \\
\hline & GRSI 1st case to 2 weeks & $1.8(-1.9$ to 5.5$)$ & 0.3234 & 1.0 \\
\hline & GRSI 1000 case to 2 weeks & $-1.9(-5.4$ to 1.7$)$ & 0.2779 & 1.1 \\
\hline & CT 1 st case to 2 weeks & $-2.6(-5.7$ to 0.45$)$ & 0.0883 & 1.8 \\
\hline & & $R^{2}=0.80$ & & \\
\hline
\end{tabular}

Note: significant associations $(\mathrm{p}<0.05)$ are shown in bold, $\beta 1=$ standardized slope of the regression model, $\mathrm{CI}=$ confidence interval.

Table 4

Adjusted multiple regression analysis of standardized spreading index and risk factors for the spreading of COVID-19.

\begin{tabular}{|c|c|c|c|c|c|}
\hline \multirow[t]{2}{*}{ Variables } & & \multicolumn{3}{|l|}{ Adjusted Model } & \multirow[t]{2}{*}{ Importance Rank } \\
\hline & & $\beta_{1}(95 \% \mathrm{CI})$ & $p$ & $|t|$ & \\
\hline \multirow[t]{3}{*}{ Demographical } & Urban population, \% & $-2.5(-6.6$ to 1.6$)$ & 0.2023 & 1.4 & 8 \\
\hline & Smoking prevalence, $\%$ & $3.1(-1.5$ to 7.6$)$ & 0.1639 & 1.5 & 7 \\
\hline & Overweight prevalence, $\%$ & $4.7(0.99$ to 8.4$)$ & 0.0187 & 2.9 & 2 \\
\hline \multirow[t]{2}{*}{ Environmental } & Temperature, ${ }^{\circ} \mathrm{C}$ & $-0.80(-5.9$ to 4.3$)$ & 0.7340 & 0.35 & 13 \\
\hline & Relative humidity, \% & $-0.18(-3.4$ to 3.0$)$ & 0.9008 & 0.13 & 15 \\
\hline Socioeconomic & Healthcare spending, USD & $0.80(-2.8$ to 4.4$)$ & 0.6238 & 0.51 & 11 \\
\hline \multirow[t]{5}{*}{ Government Intervention } & Number of days to impose lockdown from first case, number of days & $5.0(-0.49$ to 11$)$ & 0.0693 & 2.1 & 4 \\
\hline & Total number of cases on first lockdown, number of cases & $0.36(-4.1$ to 4.9$)$ & 0.8607 & 0.18 & 14 \\
\hline & GRSI 1st case to 2 weeks & $1.8(-3.3$ to 7.0$)$ & 0.4468 & 0.80 & 9 \\
\hline & GRSI 1000 case to 2 weeks & $-1.1(-7.0$ to 4.8$)$ & 0.6855 & 0.42 & 12 \\
\hline & CT 1st case to 2 weeks & $-3.5(-7.8$ to 0.73$)$ & 0.0939 & 1.9 & 6 \\
\hline
\end{tabular}

Adjusted Variables: Total population, Population density, $\mathrm{p} / \mathrm{km},{ }^{2}$ Number of days from global 1st case to adjudged peak, Number of days from global 1st case to country's 1st case. 
$\mathrm{PM}_{2.5}\left(\beta_{1}=4.2, p=0.0066,|\mathrm{t}|=3.2\right)$ was significant amongst environmental variables. For government intervention, the number of days to impose lockdown from first case $\left(\beta_{1}=5.5, p=0.0201,|\mathrm{t}|=2.6\right)$ was significant. Among the socio-economic variables, literacy rate $\left(\beta_{1}=3.3\right.$, $p=0.0386,|\mathrm{t}|=2.3)$ and per capita income $\left(\beta_{1}=3.6, p=0.0464,|\mathrm{t}|=\right.$ 2.2) were significant.

However, in Table 4, after adjusting with the total population, population density, number of days from global 1st case to adjudged peak, and number of days from global 1st case to country's 1st case; overweight prevalence $\left(\beta_{1}=4.7, p=0.0187,|\mathrm{t}|=3\right)$, air pollution, $\mathrm{PM}_{2.5}\left(\beta_{1}=4.5, p=0.0127,|\mathrm{t}|=3.1\right)$ were still significant. Along with these most significant risk factors, per capita income $\left(\beta_{1}=4.2, p=\right.$ $0.0539,|\mathrm{t}|=2.2$ ), number of days to impose lockdown from first case $\left(\beta_{1}=5.0, p=0.0693,|\mathrm{t}|=2.1\right)$, literacy rate $\left(\beta_{1}=4.6, p=0.0969,|\mathrm{t}|=\right.$ $1.9)$, CT 1 st case to 2 weeks $\left(\beta_{1}=-3.5, p=0.0939,|\mathrm{t}|=1.9\right)$, and smoking prevalence $\left(\beta_{1}=3.1, p=0.1639,|\mathrm{t}|=1.5\right)$ also demonstrated relative importance while predicting the $T_{s}$.

\section{Discussion}

The most noteworthy finding of this study was that air pollution $\left(\mathrm{PM}_{2.5}\right)$ and overweight prevalence were significant variables that could be important for controlling the multiple waves with new variant of COVID-19 effectively.

To our knowledge, this was the first study that accounted for the total number of tests by considering the standardized spreading index $\left(T_{s}\right)$. Prior studies considered total daily cases or COVID-19 positive cases in a certain population ${ }^{8}$ or the total confirmed cases based on a specific date. ${ }^{9}$ The total number of confirmed COVID-19 cases was dependent on the number of tests performed by a country. Most countries adopted different policies while testing the population based on their capabilities of supplying testing kits. Therefore, to remove the effect of unequal testing and understand the true nature of the spreading of COVID-19, we standardized our outcome measures with total tests. Furthermore, different countries had a surge of COVID-19 cases at different times, which might create a timeline bias in the analysis for a specific date. To remove the timeline bias, we adjusted the timeline of the spreading index. To realize that, we selected a particular point from the daily active cases curve to get the $T_{s}$ for all countries. This made our selection of the spreading index more controlled and robust.

Since MLR analysis provides a way of adjusting for potentially confounding variables, we adjusted our model for the total population, the population density $\left(\mathrm{p} / \mathrm{km}^{2}\right)$, the number of days from global 1st case to adjudged peak, and the number of days from global 1st case to country's 1 st case considering as the possible confounding variables. Total population and population density $\left(\mathrm{p} / \mathrm{km}^{2}\right)$ were considered as the adjusting variables because densely populated countries could have more cases of COVID-19, which may be overlooked by $T_{s} \cdot{ }^{17}$ Furthermore, the number of days from the global 1st case to adjudged peak and number of days from the global 1st case to the country's 1st case could have influenced the government intervention variables. Some countries had more time to prepare for COVID-19 interventions to contain the spreading. Thus, adjusting for these variables would provide a robust estimate of the most significant variables for spreading COVID-19.

One of the main findings was countries with higher overweight prevalence were more prone to COVID-19 infection. This finding was concurrent with the previous studies, which showed that having a higher weight may increase the chance of getting affected by COVID-19.

${ }^{3}$ One of the pathways that the COVID-19 enters the human body is through the angiotensin-converting enzyme 2 (ACE2) receptors in cells. The higher concentration of ACE2 expression in the fat tissue in overweight people might increase their risk of COVID-19. ${ }^{18}$ Furthermore, overweight individuals may have a compromised immune system, resulting in an increased risk of infection. ${ }^{19}$ Therefore, it may be conceivable that the overweight population is more vulnerable to COVID-19.
Besides the overweight population, we found air pollution was one of the significant variables affecting the spreading of COVID-19. Furthermore, our correlation analysis showed that the air pollution index had a significant positive correlation with the spreading of COVID-19. Our research was in line with the prior studies which have shown that air pollution affects COVID-19 spreading. ${ }^{20}$ Previous studies showed that air pollution impairs lung immune defenses, which might increase the susceptibility to the COVID-19. ${ }^{21}$ Furthermore, $\mathrm{PM}_{2.5}$ could infiltrate the respiratory tract and directly enter alveoli, which might form viral attachment condensation nuclei. Taken together, it was conceivable that the countries with a high $\mathrm{PM}_{2.5}$ index might have a higher spreading of COVID-19.

Government intervention variables also demonstrated crucial factors for the spreading of COVID-19. Our analysis showed that the number of days to impose lockdown from the first case was an important variable. We found that the countries that imposed lockdown earlier might have a lower value of the $T_{s}$. Our results were similar to previous studies, which concluded that lockdown helped minimize the growth of COVID-19. When a country had imposed lockdown, it ensured social distancing and prevented mass gathering. A previous study has shown that the early implementation of lockdown was effective for containing the COVID-19. ${ }^{22}$ Furthermore, we found that contact tracing 1 st case to 2 weeks was another critical risk factor. Moreover, the MLR model showed that government intervention had higher importance for the $T_{s}$ than other variables. This was in line with a previous study which showed that government intervention was a more important predictor than demographical variables. ${ }^{8}$ Therefore, government intervention played an important role to contain the spreading of COVID-19.

Interestingly, we found per capita income as an essential variable for spreading COVID-19 in the MLR analysis. Our finding was aligned with the recent study, which showed that affluent countries have a higher density of older population than poor countries. ${ }^{23}$ Having a high density of older individuals made high-income countries more vulnerable to the spreading of COVID-19. Moreover, a review study suggested that confined space like central air circulating systems might potentially impact spreading viruses like COVID-19. ${ }^{24}$ As the high-income countries had more confined spaces in the office, home, public vehicles, which might increase the spreading through the ventilation system of a building. If one person is affected, the people using that same air circulation system more likely to be affected by COVID-19. Additional research is required to understand the transmission of COVID-19 in high-income countries properly.

Furthermore, the literacy rate demonstrated a slight negative correlation with $T_{s}$ while acting as a relatively important factor for predicting $T_{s}$. It could be because literate people maintained the general safety guidelines like wearing masks, handwashing, avoiding social mixing, etc. more that might lead not to spread COVID-19. Future research is necessary to understand the relationship between literacy rate and the spreading of COVID-19.

To best of our knowledge, this was the first study to include alcohol consumption as a potential risk factor, though it did not show any association with $T_{s}$. Moreover, in our study, smokers were not prone to the COVID-19, which complied with the previous studies. ${ }^{3,25}$

In our study, temperature and humidity did not demonstrate any association or relative importance with $T_{s}$. Our results were in line with a previous study that showed no association of pandemic growth with temperature. ${ }^{8}$ However, some prior studies considered a limited number of cities or countries ${ }^{20}$ found an inconsistent association (positive and negative) between $T_{s}$ and temperature or humidity.

Our study was subjected to some limitations. Firstly, the reported cases might not be the entire picture of the COVID-19 situation of a country. Many affected patients remain undetected, making it too hard for them to get a sense of accurate total case information of a country. Secondly, the sample size was small. Future researches should increase the number of countries. Thirdly, we had only considered countries that crossed the peak of the active cases from the curve until June 10, 2020. It 
could also be deduced that these significant variables were only responsible for those countries that managed to control the spreading of the COVID-19 within June 10, 2020. Fourthly, we collected data from online sources. Though we tried our best to verify the sources, there was still a possibility of some misinformation.

\section{Conclusion}

This study investigated the most significant risk factors for spreading COVID-19 by collecting data from 29 countries worldwide. Our findings suggested that countries with more air pollution $\left(\mathrm{PM}_{2.5}\right)$ and higher overweight populations are at higher risk of spreading COVID-19. Proper healthcare safety measures in areas with a higher $\mathrm{PM}_{2.5}$ value might restrain the virus. In conjunction, assessment of the risks of the overweight population might help to control multiple waves. The governments should employ follow-up strategies for accommodating these risk factors. These efforts might aid to avert a possible next waves of COVID-19 outbreak, which can turn out as a foregone conclusion to psychosocial health and the economy.

\section{Financial support}

This research did not receive any grant from funding agencies in the public, commercial, or not-for-profit sectors.

\section{CRediT authorship contribution statement}

Fazla Rabbi Mashrur: Methodology, Software, Formal analysis, Investigation, Resources, Writing - Original Draft, Visualization. Amit Dutta Roy: Methodology, Validation, Resources, Data Curation, Visualization.Anisha Parsub Chhoan: Methodology, Resources, Data Curation. Sumit Sarker: Methodology, Resources, Data Curation. Anamika Saha: Conceptualization, Review \& Editing. S.M. Naimul Hasan: Conceptualization, Review \& Editing. Shumit Saha: Conceptualization, Methodology, Validation, Writing - Review \& Editing, Supervision, Project administration.

\section{Acknowledgements}

We appreciate the anonymous reviewers for their insightful feedback to improve the quality of the paper.

\section{References}

1 Coronavirus update (live): 133,853,626 cases and 2,904,358 deaths from COVID-19 virus pandemic - worldometer. Accessed https://www.worldometers.info/coronavir us/. Accessed April 8, 2021.

2 Walker PGT, Whittaker C, Watson OJ, et al. The impact of COVID-19 and strategies for mitigation and suppression in low- and middle-income countries. Science. 2020 369(6502):413-422. https://doi.org/10.1126/science.abc0035.
3 Lusignan S de, Dorward J, Correa A, et al. Risk factors for SARS-CoV-2 among patients in the Oxford royal College of general practitioners research and surveillance centre primary care network: a cross-sectional study, 0 Lancet Infect Dis. 2020. https://doi.org/10.1016/S1473-3099(20)30371-6, 0.

4 Hastie CE, Mackay DF, Ho F, et al. Vitamin D concentrations and COVID-19 infection in UK Biobank. Diabetes Metab Syndr Clin Res Rev. 2020;14(4):561-565. https://doi. org/10.1016/j.dsx.2020.04.050.

5 Zhou F, Yu T, Du R, et al. Clinical course and risk factors for mortality of adult inpatients with COVID-19 in Wuhan, China: a retrospective cohort study. The lancet. 2020;395(10229):1054-1062. https://doi.org/10.1016/S0140-6736(20)30566-3. Published online.

6 Wu Z, McGoogan JM. Characteristics of and important lessons from the coronavirus disease 2019 (COVID-19) outbreak in China: summary of a report of 72314 cases from the Chinese Center for Disease Control and Prevention. Jama. 2020;323(13): 1239-1242.

7 Flaxman S, Mishra S, Gandy A, et al. Estimating the effects of non-pharmaceutical interventions on COVID-19 in Europe. Nature. Published online June. 2020;8:1-5. https://doi.org/10.1038/s41586-020-2405-7.

8 Jüni $\mathrm{P}$, Rothenbühler M, Bobos $\mathrm{P}$, et al. Impact of climate and public health interventions on the COVID-19 pandemic: a prospective cohort study. Can Med Assoc J. 2020;192(21):E566-E573. https://doi.org/10.1503/cmaj.200920.

9 Wu Y, Jing W, Liu J, et al. Effects of temperature and humidity on the daily new cases and new deaths of COVID-19 in 166 countries. Sci Total Environ. 2020;729:139051. https://doi.org/10.1016/j.scitotenv.2020.139051.

10 Who | World Health Organization. Accessed https://www.who.int/. Accessed May $29,2020$.

11 timeanddate.com. Accessed June 13, 2020. https://www.timeanddate.com/.

12 World's most polluted countries in 2019 - PM2.5 ranking | AirVisual. Accessed htt ps://www.iqair.com/world-most-polluted-countries. Accessed June 9, 2020.

13 World Bank Open. Data | data. Accessed https://data.worldbank.org/. Accessed May 29, 2020.

14 Wikipedia. Accessed https://www.wikipedia.org/. Accessed May 28, 2020.

15 Coronavirus Government Response Tracker. Accessed https://www.bsg.ox.ac.uk/ research/research-projects/coronavirus-government-response-tracker. Accessed May $28,2020$.

16 Which countries do COVID-19 contact tracing? Our World in Data. Accessed https://ourworldindata.org/grapher/covid-contact-tracing. Accessed July 26, 2020.

17 Rocklöv J, Sjödin H. High population densities catalyse the spread of COVID-19. J Trav Med. 2020;27(3). https://doi.org/10.1093/jtm/taaa038.

18 Kassir R. Risk of COVID-19 for patients with obesity. Obes Rev. 2020;21(6). https:// doi.org/10.1111/obr.13034.

19 Falagas ME, Kompoti M. Obesity and infection. Lancet Infect Dis. 2006;6(7):438-446. https://doi.org/10.1016/S1473-3099(06)70523-0.

20 Zhu Y, Xie J, Huang F, Cao L. Association between short-term exposure to air pollution and COVID-19 infection: evidence from China. Sci Total Environ. 2020;727: 138704. https://doi.org/10.1016/j.scitotenv.2020.138704.

21 Olivieri D, Scoditti E. Impact of environmental factors on lung defences. Eur Respir Rev. 2005;14(95):51-56. https://doi.org/10.1183/09059180.05.00009502.

22 Roy S. COVID-19 pandemic: Impact of lockdown, contact and non-contact transmissions on infection dynamics. MedRxiv. 2020. https://doi.org/10.1101/ 2020.04 .04 .20050328$.

23 Schellekens P, Sourrouille D. COVID-19 Mortality in Rich and Poor Countries: A Tale of Two Pandemics? Washington, DC: World Bank; 2020. https://doi.org/10.1596/18139450-9260.

24 Jayaweera M, Perera H, Gunawardana B, Manatunge J. Transmission of COVID-19 virus by droplets and aerosols: a critical review on the unresolved dichotomy. Environ Res. 2020;188:109819. https://doi.org/10.1016/j.envres.2020.109819.

25 González-Rubio J, Navarro-López C, López-Nájera E, et al. A systematic review and meta-analysis of hospitalised current smokers and COVID-19. Int J Environ Res Publ Health. 2020;17(20). https://doi.org/10.3390/ijerph17207394. 